\title{
THE ADDICTIVE PERSONALITY: MYTH OR CORNERSTONE OF PREVENTION AND TREATMENT?
}

\author{
Donna L. Roberts \\ PhD, Department of Social Sciences \& Economics, Embry-Riddle Aeronautical University (USA)
}

\begin{abstract}
The concept of an addictive personality offers an attractive and intuitive construct for defining the parameters of prevention, diagnosis and treatment of substance abuse and addictive disorders. However, despite the intellectual and practical appeal, it remains controversial, with researchers and practitioners heavily debating its fundamental validity. In a seminal research study, Alan R. Lang, in conjunction with the US National Academy of Science, found that while there was no single identifiable personality type that could be used to exclusively determine susceptibility to addiction or constitute an "addictive personality," there are, however, significant personality factors that tend to underlie addictive behavior. Specifically, these included, impulsivity, sensation seeking, nonconformity, social alienation, tolerance for deviance, and heightened stress coupled with lack of coping skills. Proponents of the addictive personality paradigm argue that these common characteristics represent critical information for intervention and treatment, as well as in the realm of development and prevention. Conversely, opponents contend that not only does empirical research not support the conclusion, but neither does the theoretical framework of addiction as disease. They contend that this view is deterministic and undermines the complex and multifaceted nature of addiction, thus limiting the approaches to treatment and potentially increasing the stigma associated with addictive disorders. Currently, most researchers and practitioners would argue against the notion of a deterministic addictive personality, but consider the potential of individual personality factors to influence behavior in both positive and negative ways and thus, incorporate relevant strategies into a comprehensive treatment plan.

As we now face a global epidemic of opioid abuse that surpasses previous waves of drug use in both magnitude and severity, perhaps it is time to reevaluate the role of personality as a contributor in both the development and rehabilitation of addiction and how such information, taken in context with other relevant factors, can best serve to combat the widespread epidemic.
\end{abstract}

Keywords: addiction, personality, addictive personality, substance abuse

\section{Introduction - personality, addiction and the addictive personality defined}

Psychologists have defined personality as "the set of psychological traits and mechanisms within the individual that are organized and relatively enduring and that influence his or her interactions with, and adaptations to, the intrapsychic, physical and social environments" (Larsen \& Buss, 2018, p. 4). As such, it represents a comprehensive and stable characterization of an individual.

According to the American Society of Addiction Medicine, addiction is "a primary, chronic disease of brain reward, motivation, memory and related circuitry. Dysfunction in these circuits leads to characteristic biological, psychological, social and spiritual manifestations. This is reflected in an individual pathologically pursuing reward and/or relief by substance use and other behaviors. Addiction is characterized by inability to consistently abstain, impairment in behavioral control, craving, diminished recognition of significant problems with one's behaviors and interpersonal relationships, and a dysfunctional emotional response" (ASAM, 2019, para. 1).

Thus, consideration of an addictive personality assumes that the tendency to adopt and maintain these addictive behaviors is woven into the very fabric of the individuals overarching patterns of thought, emotion and manner of behaving. This perspective posits that certain personality types are more predisposed - some even assert destined - to develop and maintain psychological and/or physical addiction. 


\section{The addictive personality - myth or reality?}

The designation of 'addictive personality' does not appear among the ten personality disorders of the current Diagnostic and Statistical Manual of Mental Disorders (DMS), Fifth Edition. Furthermore, the DSM-5 lists nine specific types of substance addictions - alcohol; caffeine; cannabis; hallucinogens; inhalants; opioids; sedatives, hypnotics, and anxiolytics; stimulants; and tobacco, with substance abuse and substance dependence measured on a continuum from mild to severe. These types are further described by eleven distinct criteria, none of which refer to personality characteristics (American Psychiatric Association, 2013).

While the terms 'addictive personality' and 'addictive personality disorder' are largely not officially recognized in academic and professional research and practice, they abound in the general dialogue, having their roots in the fundamental stereotype of addiction as a 'character disorder' and the underlying desire to be able to cleanly and clearly identify a targeted cause in order to modify its effect. These designations appear in venues as diverse as Healthguidance.org, HighBeam Research (operated by Cengage Learning), Psychology Today, the New York Times, Addiction.com, Medic8.com, Recovery.org and WebMD.com. While these sources are not generally considered scholarly research, they no doubt have influence upon the social consciousness as well as aspects of the recovery movement.

Researchers have long been interested in identifying individuals at risk for developing substance abuse disorders. With respect to distinguishing individual differences, the trait of extraversion was frequently targeted for examination. Specifically, early on, various researchers hypothesized that individuals respond differently to alcohol consumption based on their level of extraversion (Eysenck, 1957; McDougall, 1929; Sher \& Wood, 2005). While some correlations have been noted, the research findings have proven inconsistent and have not supported a general association between specific temperaments and addictive tendencies.

More recently, the concept became popularized in the social consciousness in the 1980s when Alan R. Lang conducted seminal research as a meta-analysis in an attempt to determine the nature of an addictive personality, if, in fact, one existed. His intention therein was stated as a practical and applied purpose - "If we can better identify the personality factors, they can help us devise better treatment and can open up new strategies to intervene and break the patterns of addiction" (Lang, 1983, p. 235). Lang's research, conducted for the United States National Academy of Sciences, concluded that, "While there is no single set of traits that is definitive of an 'addictive personality', several 'significant personality factors' exist, including: 1) impulsivity; 2) sensation-seeking; 3) non-conformity combined with weak commitment to socially valued goals for achievement; 4) social alienation and tolerance for deviance; and 5) heightened stress coupled with a lack coping skills" (Lang, 1983, p. 233). While not representative of a personality type per se, these conclusions did highlight aspects of trait and temperament that may play a significant role in the development of sustainment of addictive behaviors.

Proponents of the view that personality plays an influential role in addiction argue,

There is little question of whether personality is associated with problematic alcohol involvement (such as alcohol use disorders; AUDs); it clearly is. However, the question remains: how or why is personality related to risky drinking and AUDs? Although the identification of an 'addictive personality' (i.e., a specific configuration of personality characteristics linked to addictive behaviors) has largely been abandoned, numerous studies demonstrate links between specific personality traits and problematic alcohol involvement. More specifically, although traits related to impulsivity/disinhibition appear to demonstrate the most robust and consistent relation with alcohol involvement, all five-factor traits (i.e., openness to experience, conscientiousness, extraversion, agreeableness, neuroticism) have been shown to correspond, with varying degrees of consistency, to alcohol use and outcomes (Sher, Trull, Bartholow, and Vieth, 1999, Malouff, Thorsteinsson, Rooke, and Schutte, 2007, Trull and Sher, 1994). (Littlefield, Littlefield, \& Sher, 2010).

Despite the equivocal results, research continues to examine potential correlations between personality-like influences and the development of addiction. Building on the previous research, Whiteside and Lynam (2001) employed factor analyses to identify four distinct personality facets related with impulsive-like behavior: sensation seeking, lack of planning, lack of persistence, and urgency (acting rashly when distressed). Other researchers have explored associations between specific traits and their related behaviors (Cyders et al., 2007, Dick et al., 2010; Smith et al., 2007). Figure 1 represents the 
Psychobiological Model of Temperament and Character which depicts the relationship between personality and habit systems, an integral aspect of addictive tendencies (Cloninger, 1994). Still others have examined the relationship between motives related to addictive behaviors and personality traits (Grant, Stewart, O’Connor, Blackwell, \& Conrod, 2007). Despite these efforts, clear and consistent connections to broad personality traits and types remain elusive.

Figure 1. Psychobiological Model of Temperament and Character (Cloninger, 1994).

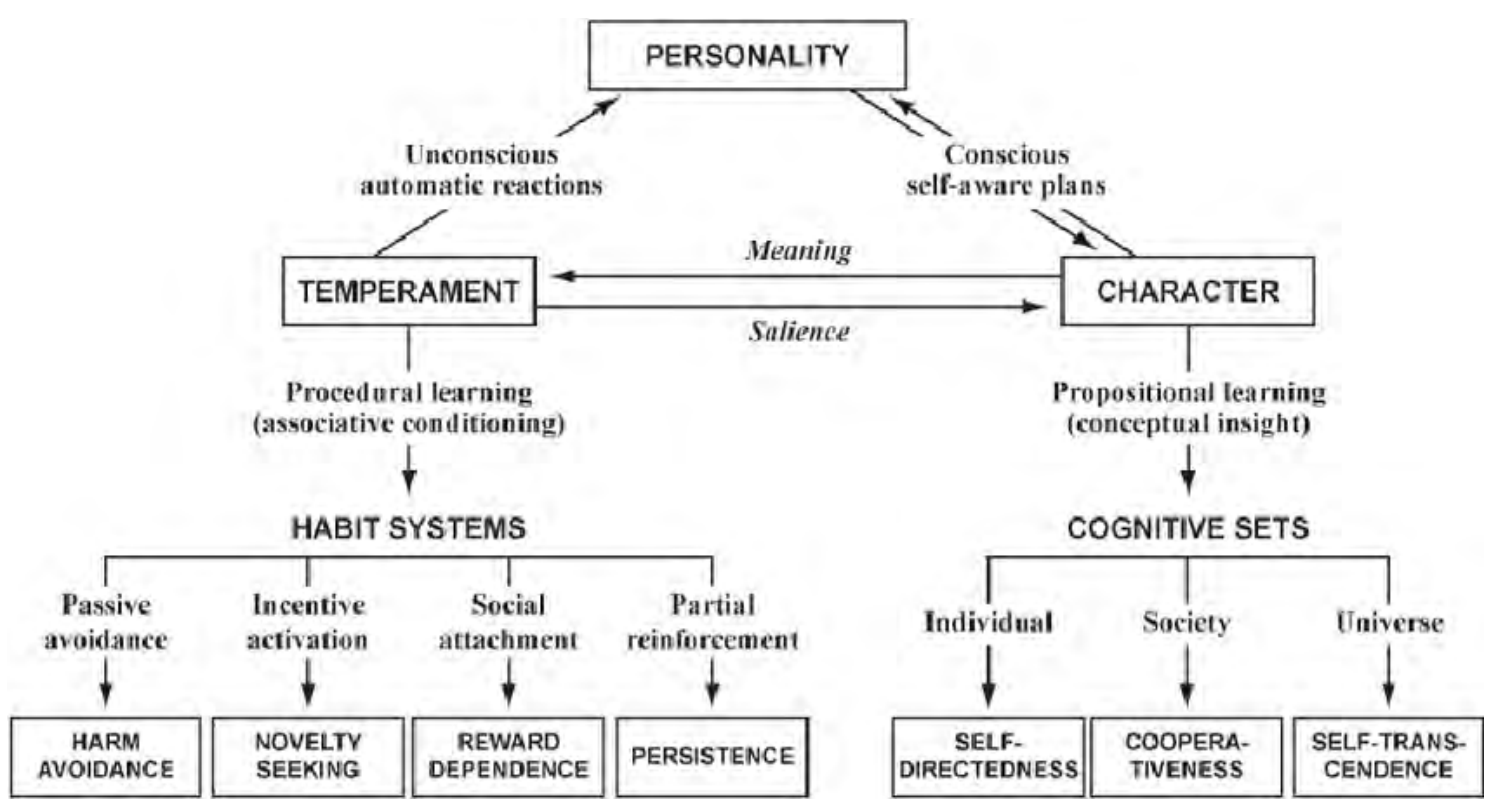

\section{Conclusion}

The fact that the empirical research does not conclusively support a clear and defined picture of an addictive personality, is not surprising, but nor does it negate the potential insights to be gained by considering personality as an important factor in both the development and recovery of substance abuse disorders. Empirical research that attempts to yield consistent predictive results from personality research often instead yields equivocal results, in part due to the difficulty in determining a comprehensive yet specific framework for defining personality.

There is significant debate about whether personality, as we currently define and measure it, even provides a valid and reliable explanation and/or predictor of behavior. Beyond that, there is significant disagreement about how to define personality in a measurable, specific, yet comprehensive way. Among themselves, personality psychologists do not agree various fundamental aspects of the construct - e.g., trait vs. type - and thus, do not embrace a single set of stable personality measures that consistently yield valid and reliable predictive results. Furthermore, there is sufficient evidence that factors other than personality profiles - e.g., situational aspect, abilities and motivation - also influence performance (George \& Jones 2011). Equivocal results have indeed been the status quo for decades of research linking personality to specific behavior.

Personality and addiction both represent complex constructs with numerous interacting variables. Despite efforts of researchers to refine and fine tune measurements, methodologies and procedures, results have provided few direct links between the variables that comprise these complex constructs. Human behavior in any context is always a complex and multifaceted combination of various internal and external variables working in concert to produce what might appear as a singular aspect of behavior. It is, as the Gestalists argue, more than the sum of its parts.

That said, because a concept (particularly a concept as intuitive and fundamental as personality) has not been perfectly honed, in an empirical sense, it does not mean that it has no clinical value. When we focus our microscope down to a more micro level, we see that addiction and attempts at recovery, represent individual stories of pain and healing, strength and weakness, failure and success. It is, after all, this level at which true change is made and at which the real purpose of psychology - understanding the human condition in order to make it better - exists. Therefore, any tool, any construct, any conceptualization that leads to growth and recovery of the human spirit is valid beyond its psychometric properties. 


\section{References}

American Psychiatric Association (APA). (2013). Diagnostic and statistical manual of mental disorders (5th ed.). Arlington, VA: Author.

American Society of Addiction Medicine (ASAM). (2019). Definition of addiction. Retrieved from: https://www.asam.org/resources/definition-of-addiction

Cloninger C. R. (1994) Temperament and personality. Current Opinions in Neurobiology, (4), 266-273

Cyders, M. A., Smith, G. T., Spillane, N. S., Fischer, S., Annus, A. M., \& Peterson, C. (2007). Integration of impulsivity and positive mood to predict risky behavior: Development and validation of a measure of positive urgency. Psychological Assessment, 19, 107- 118.

Dick, D. M., Smith, G., Olausson, P., Mitchell, S. H., Leeman, R. F., O’Malley, S. S., et al. (2010). Understanding the construct of impulsivity and its relationship to alcohol use disorders. Addiction Biology, 15, 217- 226.

Eysenck, H. J. (19957). Drugs and personality I. Theory and methodology. The British Journal of Psychiatry, 103:119-131.

George, J., \& Jones, G . (2011). Understanding and managing organizational behavior. (6 ${ }^{\text {th }}$ ed.). Upper Saddle River, NJ: Prentice Hall.

Grant, V. V., Stewart, S. H., O’Connor, R. M., Blackwell, E., \& Conrod, P. J. (2007). Psychometric evaluation of the five-factor Modified Drinking Motives Questionnaire-Revised in undergraduates. Addictive Behaviors, 32, 2611-2632.

Lang, A. R. (1983). "Addictive Personality: A Viable Construct?". In Levison, Peter K., Gerstein, Dean R., Maloff, Deborah R. Commonalities in Substance Abuse and Habitual Behavior. New York, NY: Lexington Books. pp. 157-236.

Larsen, R. R., \& Buss, D. M. (2017). Personality psychology: Domains of knowledge about human nature, $6^{\text {th }}$ edition. New York, NY: McGraw-Hill.

Littlefield, A. K., Littlefield, A. K., \& Sher, K. J. (2010). The multiple, distinct ways that personality contributes to alcohol use disorders New York, NY: Wiley-Blackwell Publishing Ltd. doi:10.1111/j.1751-9004.2010.00296.x

Malouff, J., Thorsteinsson, E., Rooke, S., \& Schutte, N. (2007). Alcohol involvement and the five factor model of personality: A meta-analysis. Journal of Drug Education, 37, 277- 294.

McDougall W. (1929). The chemical theory of temperament applied to introversion and extroversion. The Journal of Abnormal and Social Psychology, (24), 293-309

Sher, K. J., Trull, T. J., Bartholow, B., \& Vieth, A. (1999). Personality and alcoholism: Issues, methods, and etiological processes. In H. Blane \& K. Leonard (Eds.), Psychological Theories of Drinking and Alcoholism, 2nd ed., pp. 55-105). New York, NY: Plenum.

Sher, K. J., Wood M. D. (2005). Subjective effects of alcohol II: Individual differences. In: Earleywine M, Editor. Mind altering drugs: Scientific evidence for subjective experience, pp. 86-134. New York, NY: Oxford. pp. 86-134.

Smith, G. T., Fischer, S., Cyders, M. A., Annus, A. M., Spillane, N. S., \& McCarthy, D. M. (2007). On the validity and utility of discriminating among impulsivity-like traits. Assessment, 14, $155-170$.

Trull, T. J., \& Sher, K. J. (1994). Relationship between the five-factor model of personality and Axis I disorders in a nonclinical sample. Journal of Abnormal Psychology, 103, 350- 360.

Whiteside, S. P., \& Lynam, D. R. (2001). The five factor model and impulsivity: Using a structural model of personality to understand impulsivity. Personality and Individual Differences, 30, 669-689. 